\title{
Homogeneous electron-transfer of chlorophyll and its derivative chlorophyllin at gold electrode
}

Transferencia electrónica homogénea de clorofila y su derivado clorofilina en un electrodo de oro

Author:

Alhasan $\mathbf{H}^{1}$

Alahmadi $\mathbf{N}^{2}$

Wadhawan $\mathrm{J}^{3}$

\section{SCIENTIFIC RESEARCH}

How to cite this paper:

Alhasan H, Alahmadi N, Wadhawan, Homogeneous electron-transfer of chlorophyll and its derivative chlorophyllin at gold electrode. Innovaciencia. 2019; 7 (1): 1-17. http://dx.doi.org/10.15649/2346075X.509

Reception date:

Received: 16 February 2019

Accepted: 12 April 2019

Published: 25 October 2019

Keywords:

Homogeneous Electron Transfer, Chlorophyll, Chlorophyllin, Gold electrode.

\begin{abstract}
Introduction: Chlorophyll is a light harvesting pigment, which absorbs light in the visible spectrum of sunlight and promotes electron transfer, Chlorophyllin (CHL) is One of the most important derivative molecules of chlorophyll. Nowadays, chlorophyll pigment and its derivatives are utilised in organic photosynthetic solar cells for their desirable photovoltaic properties. Cyclic voltammetry (CV) is an essential technique. It is extensively used to study electroactive species to interpret the intermediates of reactions, supply information about the thermodynamics of oxidation-reduction reactions and elucidate the kinetics of electron transfer reactions. Materials and Methods: Prior to the electrochemical study, the working gold $(\mathrm{Au})$ electrode surface was prepared by immersing it in the various concentrations of chlorophyllin for a period time. The electrolyte was degassed by using $\mathrm{N}_{2}$ for approximately 30 minutes inside a Faraday cage before any electrochemical experiment was performed. A three electrode system was used with, $\mathrm{Ag} / \mathrm{AgCl}$ as a reference electrode, graphite as a counter and the working electrode $(\mathrm{Au})$. Results and Discussion: As a route to develop new chemical systems for artificial photosynthesis, this work reports the effectiveness of different parameters in transferring electrons between chlorophyllin (CHL) pigment and the working electrode surface (gold). These parameters such as the adsorption time, the electrolyte nature and concentration and chlorophyllin concentration are investigated. The use of chlorophyllin as a redox mediator is examined, with a gold electrode being employed. The importance of gold electrode surface preparation in determining the mechanism of redox is described, and the environment of adsorption process of the different concentrations of chlorophyllin on the surface of the gold electrode has been elucidated in this study. Conclusiones: The electrochemical method showed that the cyclic voltammetry responses of studied adsorption chlorophyllin pigment on the gold electrode were more efficient. In addition, the redox reaction was successful electrochemically in aqueous solution than the organic solution. It was suggested that electrons reduce to the chlorophyllin pigment by adding active species in the bulk solution homogeneous transfer. Finally, detections of chl on spinach leaves using various methods are reported.
\end{abstract}

\footnotetext{
Department of Chemistry, Environmental Research and Studies Centre, University of Babylon, hudasami47@yahoo.com Department of Chemistry, Faculty of Sciences, University of Jeddah, Kingdom of Saudi Arabia, nsmalahmadi@gmail.com Faculty of Science and Engineering, School of Engineering and Computer Science, University of Hull, United Kingdom, j.wadhawan@hull.ac.uk
} 


\section{INTRODUCTION}

Natural pigments play a crucial role in harvesting solar energy and converting visible light into electrical energy $\stackrel{(1-4)}{ }$. The light conversion process is supported with sensitisation of numerous semiconductors by appropriate dyes ${ }_{(5,6)}$. Several organic dyes and metal complexes have been synthesised and used as sensitisers. Although the most effective sensitisers are ruthenium-based complexes, due to their properties, charge transfer between metal/ligand and absorption over wide visible range $\frac{(6,7)}{}$, they are costly to manufacture and environmentally to pollute. Therefore, an alternative method is suggested such as natural dyes from plants and fruits with low cost, high light-harvesting efficiency and eco-friendliness $\stackrel{(8-10)}{-}$. In this regard, several dyes have been used as sensitizers such as anthocyanins, carotenoids and chlorophyll which are easily extracted from natural sources (11, 12). Chlorophyllin (CHL) is the most critical derivative molecules of natural green pigment $\mathrm{CHL} \stackrel{(13)}{\mathrm{C}}$, CHL as a hydrophilic molecule, is more soluble in water than chlorophyll and is more stable in moderate light, heat, oxygenated conditions, extreme absorption in the visible light and low $\mathrm{pH} \stackrel{(14-17)}{ }$. Chlorophyll and their derivatives are common light-sensitive compounds of photosensitizers and are selectively retained by tumour cells $\stackrel{(18,19)}{ }$. The therapeutic potential lies in the ability of the porphyrin structure to undergo photosensitization upon exposure to light. An illumination of the molecule converts it to a short-lived triplet excited state. Typically, sensitiser molecules in the triplet state can abstract an electron (or hydrogen atom) from, or donate an electron (or hydrogen atom) to, a substrate molecule. The anionic or cationic radicals of the sensitiser can then react with oxygen and form reactive oxygen species. These species rapidly react with some electron-rich molecules such as unsaturated lipids, amino acids, DNA-bases and so forth, thereby the interference with the normal activities of subcellular structures resulted in the injury and death of cells in proximity to the sensitiser molecule $\stackrel{(20-23)}{~}$.

Green plant chlorophyll is considered to be the electronic centre of the photosynthesis process. This pigment captures solar energy and converts it into chemical energy through many steps $\stackrel{(24-26)}{ }$. In addition, during this process chlorophyll acts as both a reductant and an oxidant due to its molecular structure (the central magnesium ion and a phytol chain),

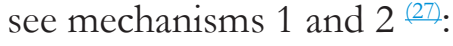

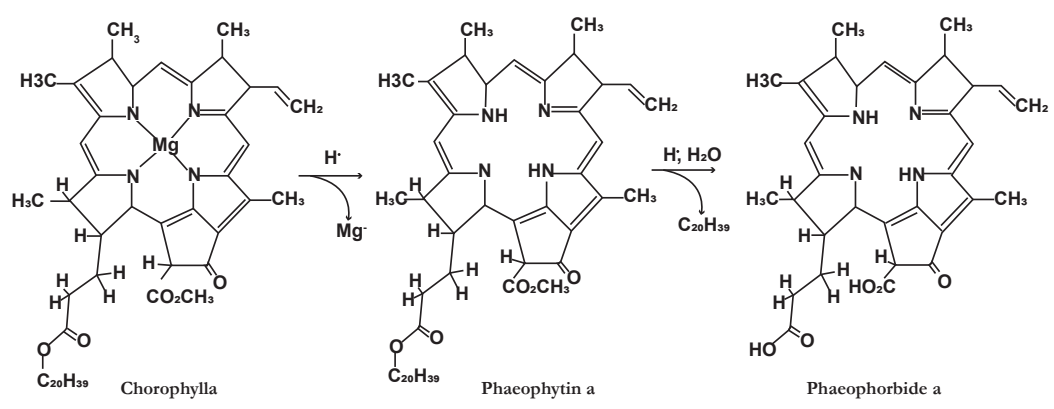

Mechanism 1. Chlorophyll a with acid
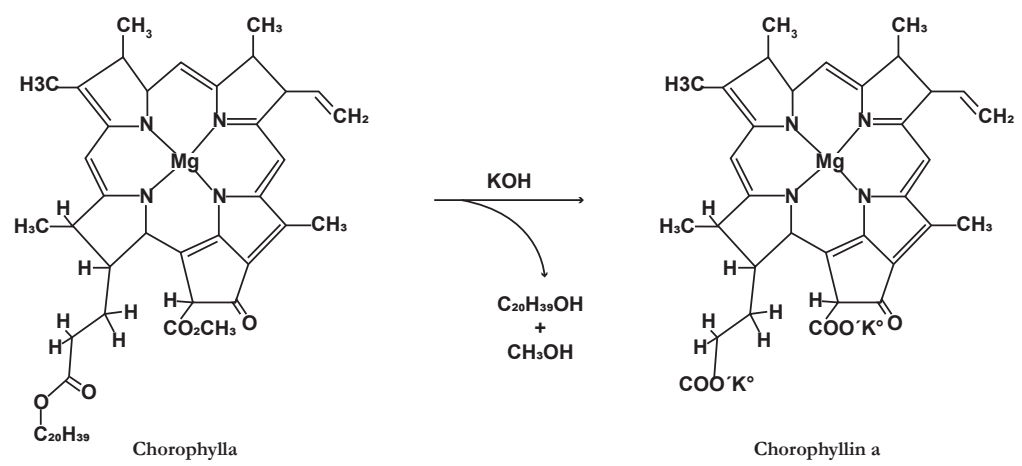

Mechanism 2. Chlorophyll a with base 
The donor-acceptor systems containing chlorophyll have, thus, been widely explored by various methods. These methods including self-assembled tetra pyrrole-carbon nanotubes for light-induced electron transfer applications, photo-induced ET between chl a and Au nanoparticles by fluorescence, polarisation transient grating technique on several chlorophylls as donor molecules and the redox potentials of chlorophylls using cyclic voltammetry (CV) and square wave voltammetry (SWV) $\frac{(22,28-30)}{\text {. Numerous }}$ investigations have been conducted on the activities of chlorophylls and their derivatives. Though, less research has been carried out on CHL. Novak et al. described oxidation mechanisms of CHL at a glassy carbon electrode using square-wave voltammetry. Therefore, more research should be done to understand the redox behaviour of CHL. Voltammetric techniques provide the comprehensive tools for investigation the electrochemical mechanisms of CHL $\stackrel{(31)}{~}$.

Metallic electrodes such as gold (AuE), silver and platinum have usually been used while materials of graphite and its derivatives such as carbon are em-

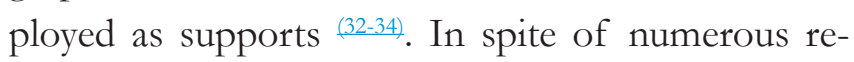
ports of oxides on gold electrodes, they are useful in electrochemical applications especially sensors constrictions due to their properties such as chemical inertness, high electrical conductivity, flexibility for

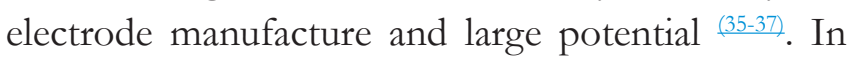
the present work, effort has been made to investigate the electron transfer induce between modified electrode with either chlorophyll or its analogues (CHL) and some species in bulk solution.

The objective of the study was to see if the oxidation catalytic activity occurred between modified electrode with chlorophyll /CHL and an aqueous solution containing some active species such as CPZ. $\mathrm{HCl}, \mathrm{L}-\mathrm{Cyst.H}$ and $\mathrm{KI}$ in the presence and absence of Triton X100 and Vitamin $\mathrm{K}_{1}$.

\section{EXPERIMENTAL SECTION REAGENTS}

All chemical reagents were used in this research without further purification. Deionised water with $18 \mathrm{M} \Omega \mathrm{cm}$ resistivity was used to prepare all aqueous solutions; the temperature was $20 \pm 3{ }^{\circ} \mathrm{C}$. The electrolyte solutions were purged for 10-30 minutes with nitrogen or Aragon. Standard solutions such as chl and CHL were prepared daily and protected from light by using aluminium foil.

Chlorophyllin, coppered trisodium salt, Hydrochloric acid $>99.99 \%$, Octyl phenol ethoxylate (TritonX100), Potassium iodide $>99.99 \%$, Phylloquinone (Vitamin K1), Acetone, Ethanol, Methanol, Hydrogen peroxide $>30 \%$, Sulphuric acid $>95 \%$, Methyl cyanide $>99.9 \%$, potassium chloride $>99.9 \%$, Argon gas 99.9\%, Nitrogen gas 99.9\%, were purchased from Alfa Aesar, Sigma-Aldrich, VWR chemicals(BDH), Fisher Scientific, BOC Gases, UK, Energas LTD

\section{INSTRUMENTATION AND EXPERIMEN- TAL SETUP}

The experimental equipment used in this research were potentiostats manufactured by Metrohm ${ }^{\circledR}$ $\mu$ Autolab Type III and equipped with General Purpose Electrochemical System (GPES)10.1 software for all voltammetric measurements, written by Metrohm ${ }^{\circledR}$. The temperature was maintained at 296 $\pm 0.5 \mathrm{~K}$ in the dark for all electrochemical experiments. In all cases, a conventional three-electrode system was employed in all experiments. Graphite as a counter electrode, and silver/silver chloride $(3 \mathrm{~mol}$ $\left.\mathrm{L}^{-1}\right)$ as a reference electrode while a working electrode is a Metrohm ${ }^{\circledR}$ gold disk electrode, ( $2 \mathrm{~mm}$ diameter, $80 \mathrm{~mm}$ length). Prior to voltammetry, all solutions were purged with free $\mathrm{N}_{2}$ or Ar gas for 30 minutes, while the experiments themselves were conducted under the stem of these gases atmosphere on the solution surface. 
In all experiments, the redox reactions were undertaken at the surface of a working electrode. Therefore, the working electrode required frequent polishing by the appropriate size of carborundum paper (400, 12002400 grade, Presi, France) with $3 \mu \mathrm{m}$ alumina paste (Presi, France). Thus, reproducible results were obtained, and the absorbed species was removed from the surface of this electrode. The UV-Visible spectrometry was undertaken using a Perkin-Elmer (USA) UV-Vis spectrophotometer, (model Bio Lambda 10), with a clear quartz cuvette of path length $1 \mathrm{~cm}$. The spectrometer was controlled using UV-Vis Chemstation software.

\section{MODIFIED WORKING ELECTRODE (MWE)}

In the past two decades, modifications of working electrodes have seen many widely differing applications in the electrochemical field. Through modification, the surface properties of the selected electrode, such as stability and sensitivity will improve, therefore it can be applied in particular areas such as electrochemical sensors and photoelectrochemical devices $\stackrel{(38-41)}{ }$. The idea underpinning modified electrodes is to localise chemical reagents on the WE surface so as to keep a locally high concentration of reactant. This can be achieved by covering the electrode surface with a mediator solution and then allowing the mediator to evaporate ${ }^{(42,43)}$. Different compounds have been used to modify WEs in this way; some reaction requirements have been achieved such as electrocatalytic, electrochemical and photo-

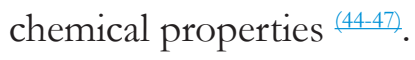

Prior to each experiment, the gold disk substrate electrode was immersed for 10 minutes in piranha solution (3:1 proportion of sulfuric acid: hydrogen peroxide $30 \%$ ). To form a smooth surface on the working electrode, it was polished with wetting cloth using $0.3 \mu \mathrm{m}$ alumina slurry for at least 60 seconds.
It was then rinsed with distilled water and dried at room temperature before use in each experiment. The working electrode was modified by immersing in the chlorophyllin copper salt solution for a period ranging from two hours to three days. After that, the modified electrode surface was rinsed with distilled water, which was coated successfully with chlorophyllin before immersing in the appropriate solution. The solutions were degassed with high-purity nitrogen before the electrochemical measurements.

\section{PREPARATION OF MEDIATOR ELEC- TROLYTE}

A mediator electrolyte plays a crucial role in reducing the resistivity of the solution and overcomes the charged migration of electroactive species ${ }^{(48-50)}$. Therefore, the mediator electrolyte must be inert and ionic for electrochemical work. In this study, a $50 / 50 \%$ ratio of aqueous/surfactant (hydrochloric acid-TritonX100) was used as supporting electrolyte. The mixture was heated, with vigorous stirring under nitrogen to $70^{\circ} \mathrm{C}$ for at least two hours, and then the mixture was allowed to cool slowly to room temperature $25^{\circ} \mathrm{C}$, before further experiments that examined chlorophyllin, plant pigment and vitamin $\mathrm{K}_{1}$.

\section{PIGMENT EXTRACTION}

The crude chlorophyll was extracted from fresh spinach leaves as described previously in protocols (51-55). The spinach was purchased from a local market. Spinach leaves (Spinacia oleracea) were separated from the stems, and then about 20 grams were weighed and mixed with an aqueous acetone solution [4:1(v/v) acetone/water], stirred for approximately two hours at room temperature. Following filtration, the solvent was removed using a rotary evaporator, and the resulting solid examined via UV/visible spectroscopy in ethanol which is absorbed light between wavelengths 300 and $800 \mathrm{~nm}$. 
RESULTS AND DISCUSSION

THE INFLUENCE OF ELECTROCHEMICAL PARAMETERS ON CHL ADSORPTION AT THE ELECTRODE SURFACE

Adsorption of the substance on the electrode surface is a phenomenon, which affects electrochemical signals. Conversely, on the electric field at an electrode surface may enlarge adsorption, with current signals that may trigger binding and unbinding of the analyte to the electrode. The binding is either a chemical bond (chemisorption) or a physical bond (physisorption). Chemisorption is stronger than physisorption, because it consists of ionic or covalent bonding of the molecules, whereas physisorption consists of weak intermolecular forces such as van der Waals' forces and dipole-dipole interactions $\stackrel{(56,57)}{ }$.

There are various conditions for the amount of active species which are adsorbed on the working elec-

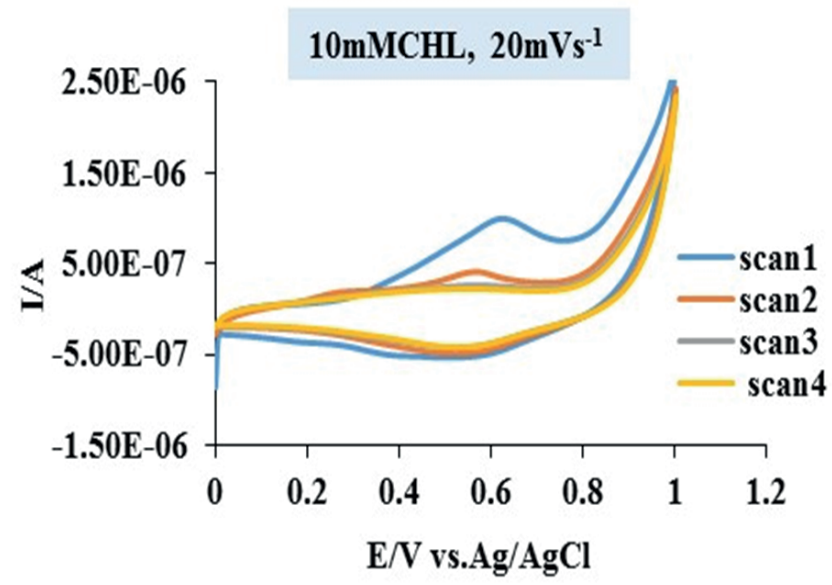

trode, such as the material of the surface, the nature of the molecules, the applied potential, temperature and so forth ${ }^{(58,59)}$. In the study presented here, some of these parameters are examined.

\section{THE INFLUENCE OF ELECTROLYTES NATURE ON THE REDOX REACTION OF CHL}

Cyclic voltammograms were recorded for the electrochemical redox reactions of $10 \mathrm{mM} \mathrm{CHL}$ on the gold electrode as working and $\mathrm{Ag} / \mathrm{AgCl}$ as a reference electrode, graphite as a counter in $0.1 \mathrm{M}$ for both inorganic ( $\mathrm{HCl})$ and organic (acetonitrile) electrolytes. Figure 1 illustrates the responses at the gold electrode, which was immersed in a CHL solution for two hours, followed by using an inorganic electrolyte $(\mathrm{HCl})$ in an electrochemical cell.

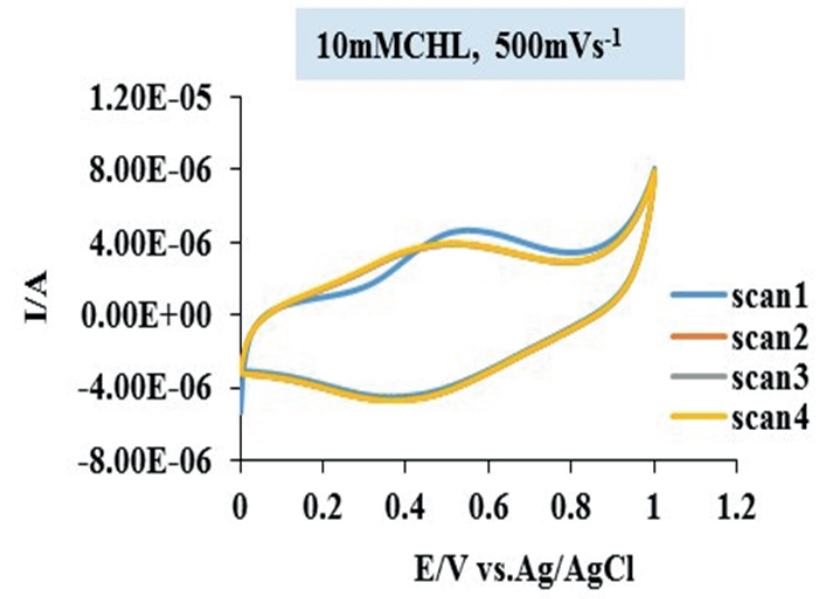

Figure 1. Cyclic voltammograms 20 and $500 \mathrm{mV} \mathrm{s}^{-1}$ are detailing the response of $10 \mathrm{mM} \mathrm{CHL}$ in $0.1 \mathrm{M}$ $\mathrm{HCl}$, which was adsorbed on the gold electrode for two hours

The voltammograms show a well-defined oxidation peak at $+0.58 \mathrm{~V}$ due to the single-electron oxidation of CHL to form the chemically stable radical cation, which is shown in the Scheme 1. Here was an increase in peak current with increasing scan rates. Thus, the gold electrode was sufficient for adsorbing CHL pigment on its surface. 


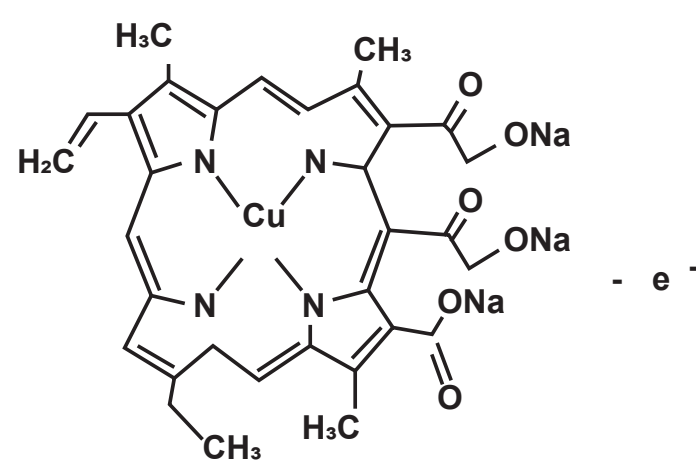
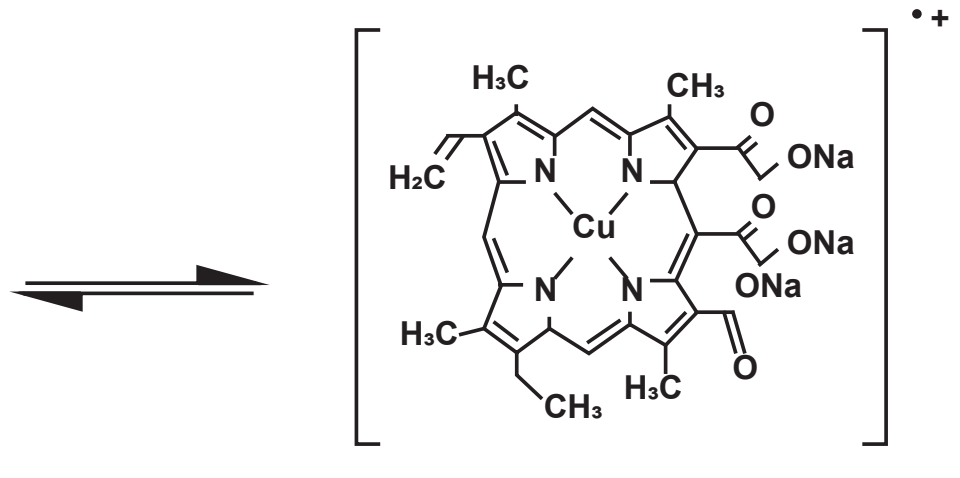

Scheme 1. one electron oxidation of CHL to obtain the cation radical

The redox catalysis of $10 \mathrm{mM}$ CHL was carried out again in $0.1 \mathrm{M}$ organic solution of acetonitrile $(\mathrm{MeCN})$, as shown in Figure 2.
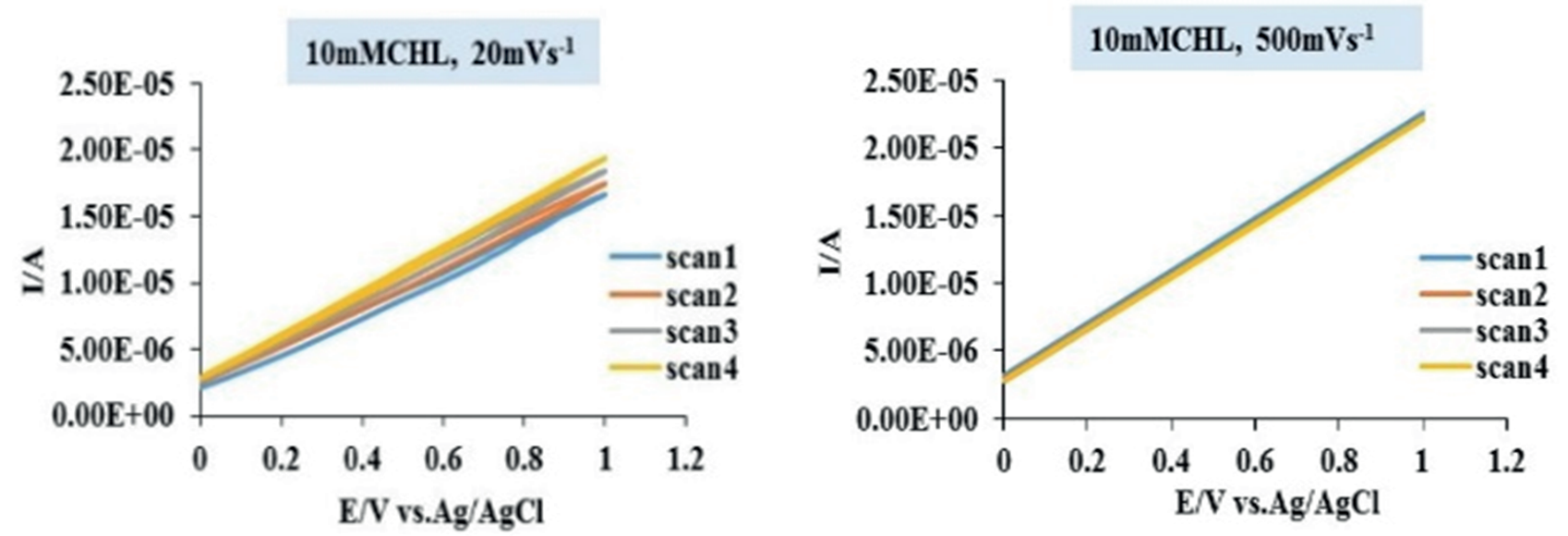

Figure 2. Cyclic voltammograms 20, and $500 \mathrm{mV} \mathrm{s}-1$ detailing the response of the CHL (10mM) in $0.1 \mathrm{M}$ acetonitrile, which was adsorbed on the gold electrode for two hours

Figure 2 reveals that there were no analogous peak currents at all scan rates the response is pure resistance indicating that the solution lacks sufficient electrical conductivity.

VOLTAMMETRY OF ADSORBED CHL PIGMENT ON THE GOLD ELECTRODE IN CONSECUTIVELY TIMES

The voltammetry of adsorbed CHL was achieved by soaking the gold electrode in $10 \mathrm{mM} \mathrm{CHL}$ for two hours, and consecutively three times of ten minutes. After which it was rinsed with deionised water prior to undertaking voltammetry in $0.1 \mathrm{M} \mathrm{HCl}$ using the same reference and counter electrodes as in the previous experiment, with scan rates 20 to $2000 \mathrm{mV}$ $\mathrm{s}^{-1}$. Figure 3 shows four consecutive voltammetry sweeps for the pigment above. 

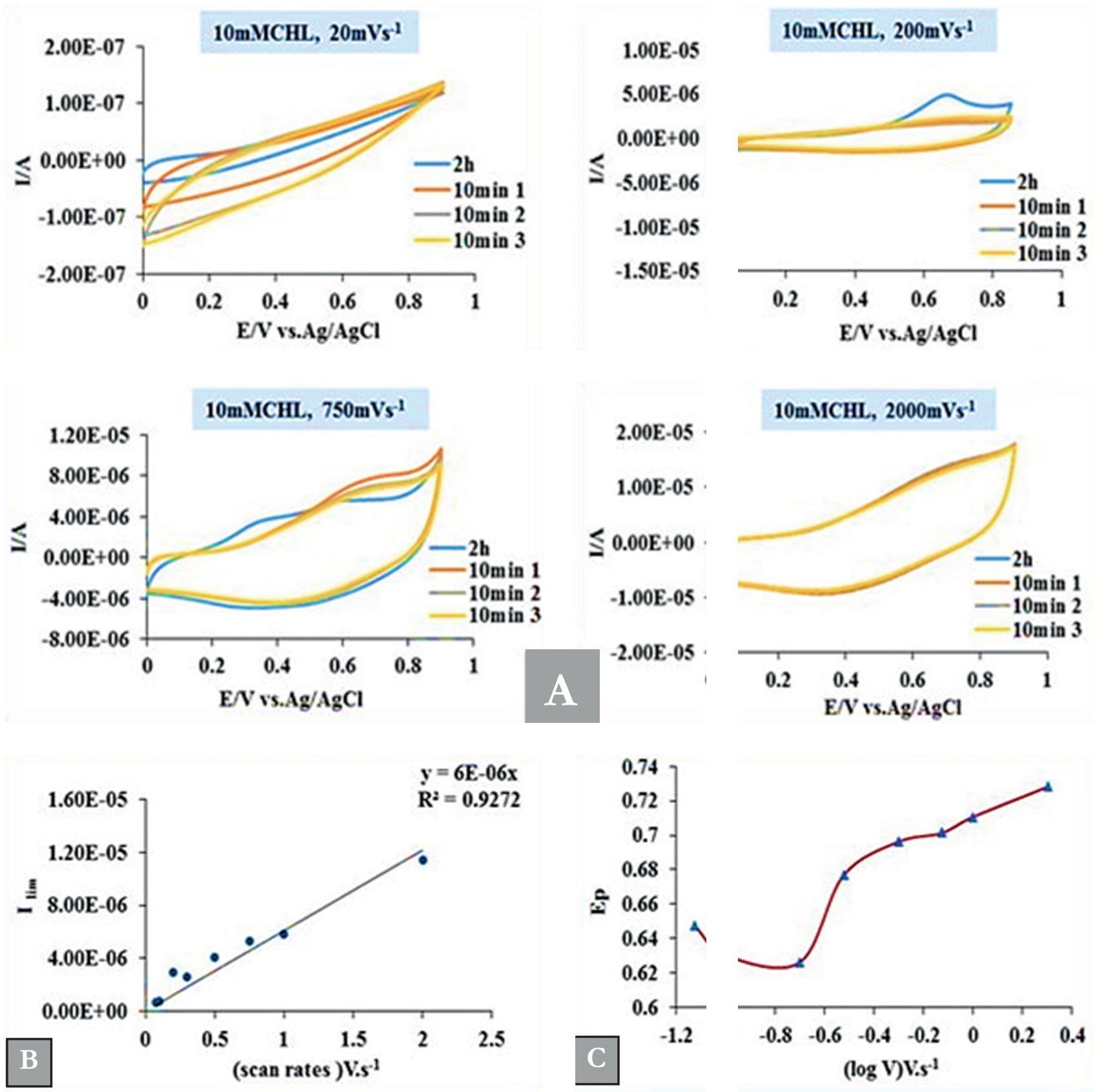

Figure 3. A. Scan rate dependence CVs of $10 \mathrm{mM} \mathrm{CHL}$ in $0.1 \mathrm{M} \mathrm{HCl}$ on AuE at 20-2000 $\mathrm{mV} \mathrm{s}^{-1}$, B. anodic current as a function of the scan rates (V) and (C). Potential as a function of the scan rates logarithms 20$2000 \mathrm{mV} \mathrm{s}^{-1}$

Figure 3(A) demonstrates the oxidation peaks via scan rates of the system. There was an increase in the peak current, which was coupled with a slight positive shift in peak potentials with an increase in scan rates from 20 to $2000 \mathrm{mV} \mathrm{s}^{-1}$ and adsorption incubation time. A plot of oxidation peak current $\left(\mathrm{I}_{\text {lim }}\right)$ against scan rates, $(\mathrm{B})$, shows a linear trend with coefficient value $\mathrm{R}^{2}$ (0.9272), which is suggestive of control diffusion. While plot (C) performs a fluctuation in the oxidative peaks of potential via logarithm of scan rates, this means that the electron transfer process is complex. 
Furthermore, the slight shift in potential with an increase in time adsorption for all scan rates highlights the one-electron oxidation of CHL is becoming more difficult, which indicates that there was no pigment adsorption on the electrode surface.

THE OXIDATIVE VOLTAMMETRY OF CHL USING SOME ELECTRO ACTIVE SPECIES

This part of the study will focus on the thermodynamics of the CHL pigment in bulk solution using cyclic voltammetry. Measurements were carried out in $0.1 \mathrm{M} \mathrm{HCl}$ with the presence of some electro active species such as L-Cyst.H, KCl, and CPZ.H. These solutions were purged with a constant flow of $\mathrm{N}_{2}$ at varying scan rates of $20-2000 \mathrm{mV} \mathrm{s}^{-1}$, and the following explains this in detail.

\section{CHL ADSORPTION ON GOLD IN THE PRESENCE OF L-CYST.H}

The adsorption of CHL on AuE was tested with varying concentrations of L-Cyst.H 0.5, 1.0, 2.0, 5.0, and $10.0 \mathrm{mM}$. The curves at Figure 4 (a) shows the dependence of net peak currents of the adsorption of CHL at the AuE surface on the concentration of L-Cst.H. In low $(0.5 \mathrm{mM})$ and high $(5$, and $10 \mathrm{mM})$ concentrations of L-Cys.H there are two anodic and cathodic peaks observed for all scan rates. The net peak potentials of the adsorption $\mathrm{CV}$ response shifted toward lower values by increasing the concentration of L-Cyst.H, indicating more facile electron transfer. Figur4 (b) shows the relationship between peak currents and scan rates for oxidative waves. The maxim current holds on approximate proportionally with scan rates as expected for surface-attached species. The plot of peak potentials via logarithms of scan rates for the oxidation peaks for all concentrations of L-Cyst.H as in Figure 5(c) generally, move to higher potential with increasing scan rate, suggesting a complex interplay between heterogeneous and homogeneous kinetics.
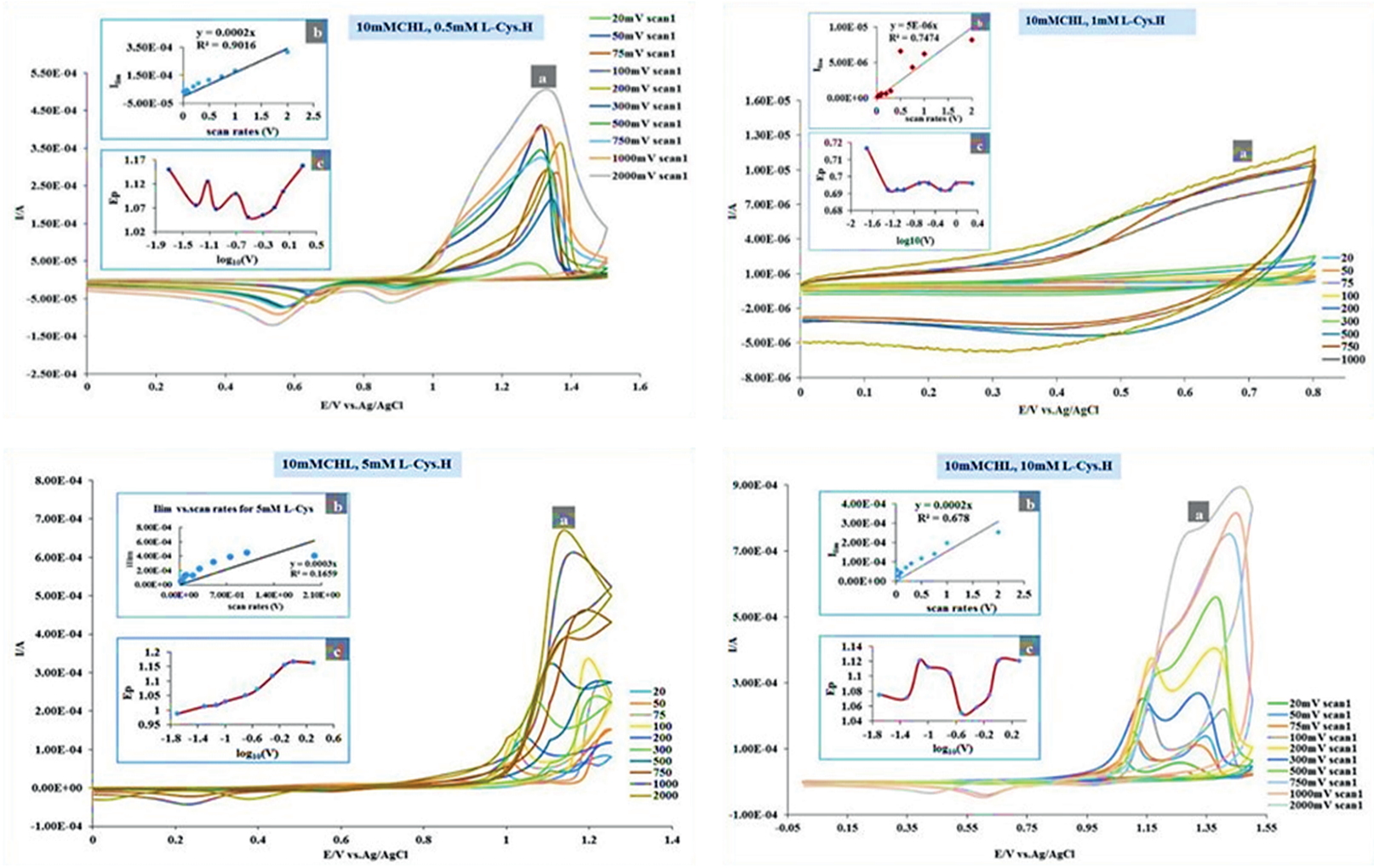

Figure 4. (a). Cyclic voltammograms for the oxidation of $10 \mathrm{mM} \mathrm{CHL,} \mathrm{two} \mathrm{hours} \mathrm{adsorption} \mathrm{on} \mathrm{the} \mathrm{gold}$ electrode with 0.5, 1.0, 5.0, and $10.0 \mathrm{mM} \mathrm{L-Cyst.H}$ in $0.1 \mathrm{M} \mathrm{HCl}$. Scan rate $20-2000 \mathrm{mV} \mathrm{s}^{-1} . \mathrm{Ag} / \mathrm{AgCl} \mathrm{elec-}$ trode served as the reference electrode, and graphite served as a counter electrode. (b). The corresponding plot of peak currents against scan rates for all concentrations of L-Cyst.H. (c). Corresponding plot of peak potentials against logarithms of scan rates for all concentrations of L-Cyst.H 
Thus, further information on the oxidation process of CHL using L-Cyst.H at concentrations higher than $10 \mathrm{mM}$ and lower than $0.5 \mathrm{mM}$ was obtained.
Here, the same procedure was undertaken as in the previous experiment, using $0.5 \mathrm{mM}$ CHL and 20 mM L-Cyst.H, see Figure 5(a).

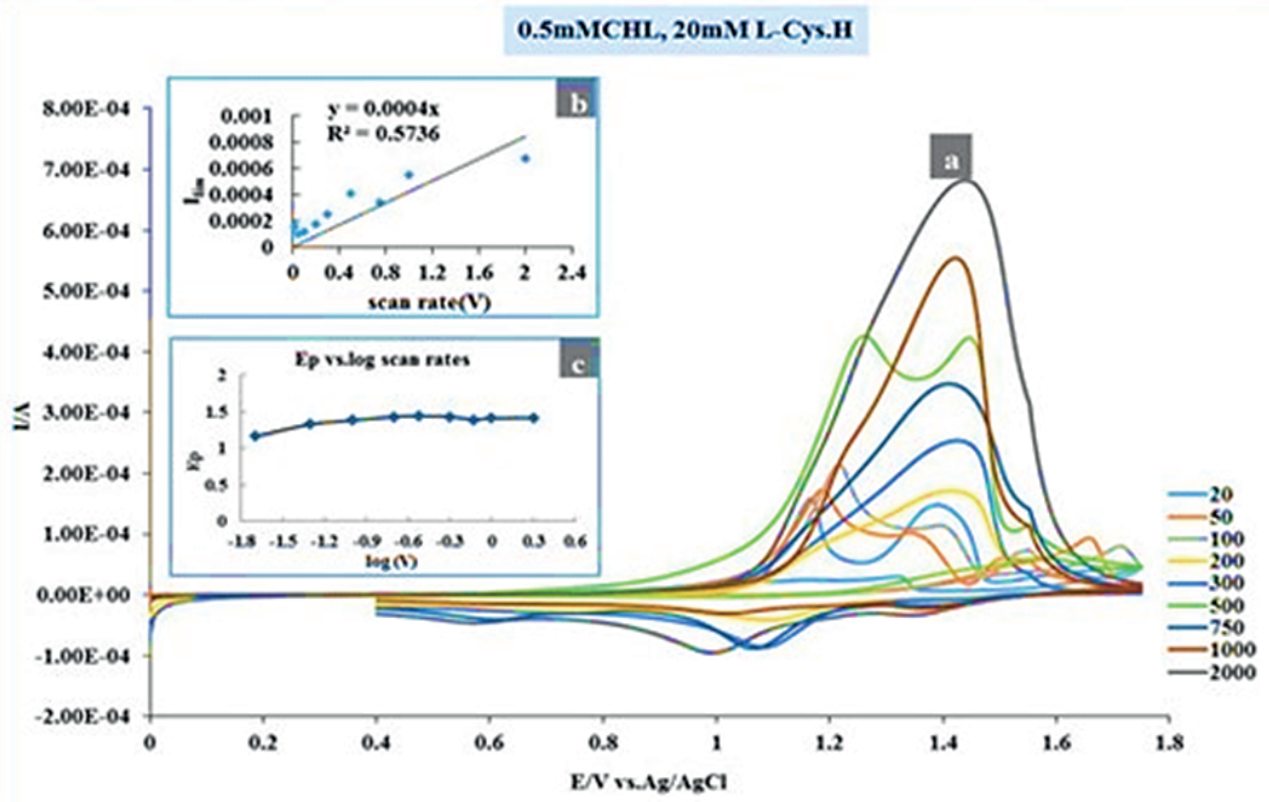

Figure 5. (a) CVs of the oxidation $0.5 \mathrm{mM}$ CHL with $20 \mathrm{mM}$ L-Cyst.H on AuE in $0.1 \mathrm{M} \mathrm{HCl}$ at variable scan rates (20-2000 $\left.\mathrm{mV} \mathrm{s}^{-1}\right)$. (b): The plot of peak currents vs. scan rates. (c): The plot of peak potentials vs log scan rates for the oxidation process

In Figure 5(a), there is the same trend as that of the oxidation of $0.5 \mathrm{mM}$ L-Cyst.H. However, the peak potential (b) gives a different trend from that of $0.5 \mathrm{mM}$ L-Cyst.H, which confirms that the oxidation process of CHL on AuE is reversible with an increase in the concentration of L-Cyst.H.
Lower concentrations of L-Cyst.H (0.2 and $0.4 \mathrm{mM})$ were considered, again following the same conditions, using $100 \mathrm{mV} \mathrm{s}^{-1}$ scan rate, see Figure 6. It can be seen that the anodic peak, which is observed at $0.5 \mathrm{~V}$, shifted to lower potential while the cathodic peak disappeared in this scan rate. In addition, it can be concluded that the reaction is chemically irreversible at low concentration of L-Cyst.H.

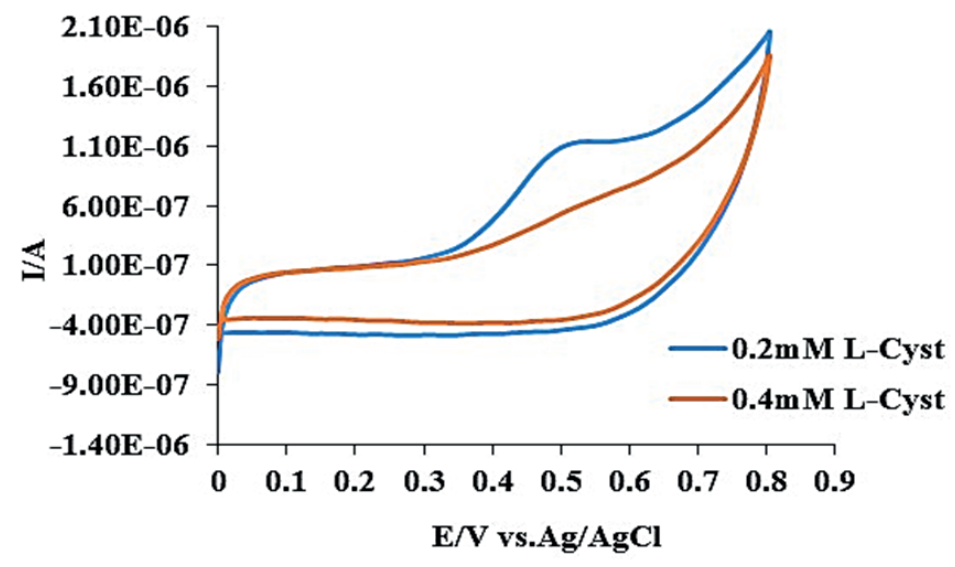

Figure 6. CVs of the oxidation $10 \mathrm{mM} \mathrm{CHL}$ with 0.2 and $0.4 \mathrm{mM} \mathrm{L-Cyst.H}$ on AuE in $0.1 \mathrm{M} \mathrm{HCl}$ at 100 $\mathrm{mV} \mathrm{s}^{-1}$ scan rate 
CHL ADSORPTION ON AUE IN THE PRESENCE OF POTASSIUM IODIDE KI

Again, cyclic voltammetry for another active species was examined. Figure 7(a) illustrates four curves of different concentrations of KI (0.01, 0.05, 0.1, and1.0 mM) with $10 \mathrm{mM} \mathrm{CHL}$ in an aqueous solution of $0.1 \mathrm{M} \mathrm{HCl}$. The peaks in the oxidative- reductive currents were observed for all concentrations of KI, which suggests that the redox process is reversible. Moreover, the linear voltammograms for concentrations 0.01 and $0.05 \mathrm{mM}$ of $\mathrm{KI}$ in the plot (b) mean that the reactions are under diffusion control. The fluctuations in the peak potentials $v s \log$ scan rates plot in (c) confirm the reversibility of the redox process, albeit with a much experimental error in potential measurement. This likely stems from the difficulty in reproducing the surface coverage.
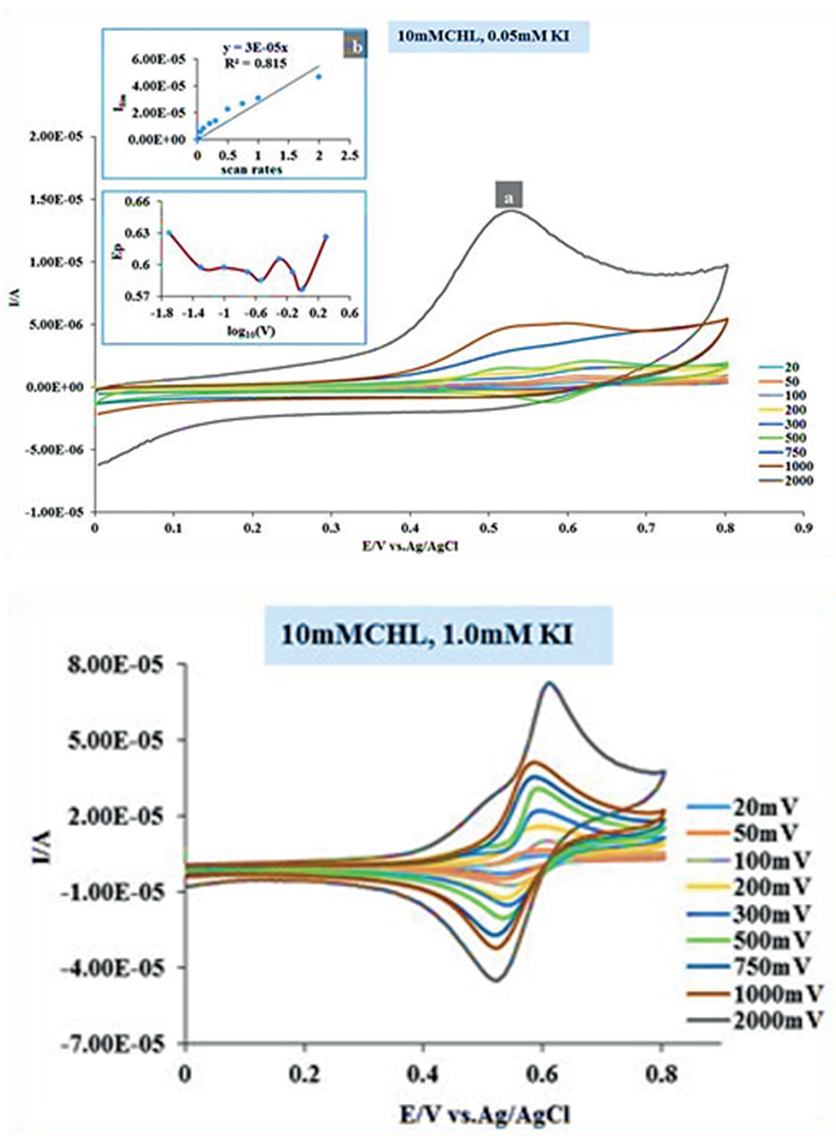

Figure 7: (a): Typical CVs observed for $10 \mathrm{mM} \mathrm{CHL}$ with varying concentrations $(0.01,0.05,0.1$ and 1.0 $\mathrm{mM}$ ) of $\mathrm{KI}$ at different scan rates $20-2000 \mathrm{mV} \mathrm{s}^{-1}$. (b): The plot of peaks current against scan rates and (c): The plot of peaks potential against logarithms of scan rates for the oxidation process CHL adsorption on AuE in the presence of CPZ.HCl

The electrochemical work with CPZ.HCl was undertaken in $0.1 \mathrm{M} \mathrm{HCl}$ at $\mathrm{AuE}$ after soaking for two hours in $10 \mathrm{mM}$ CHL pigment. This work shows a similar trend to that of the previous electroactive species, L-Cyst.H in the cases of peak currents and potential responses, see Figure 8 (a, b and c). 

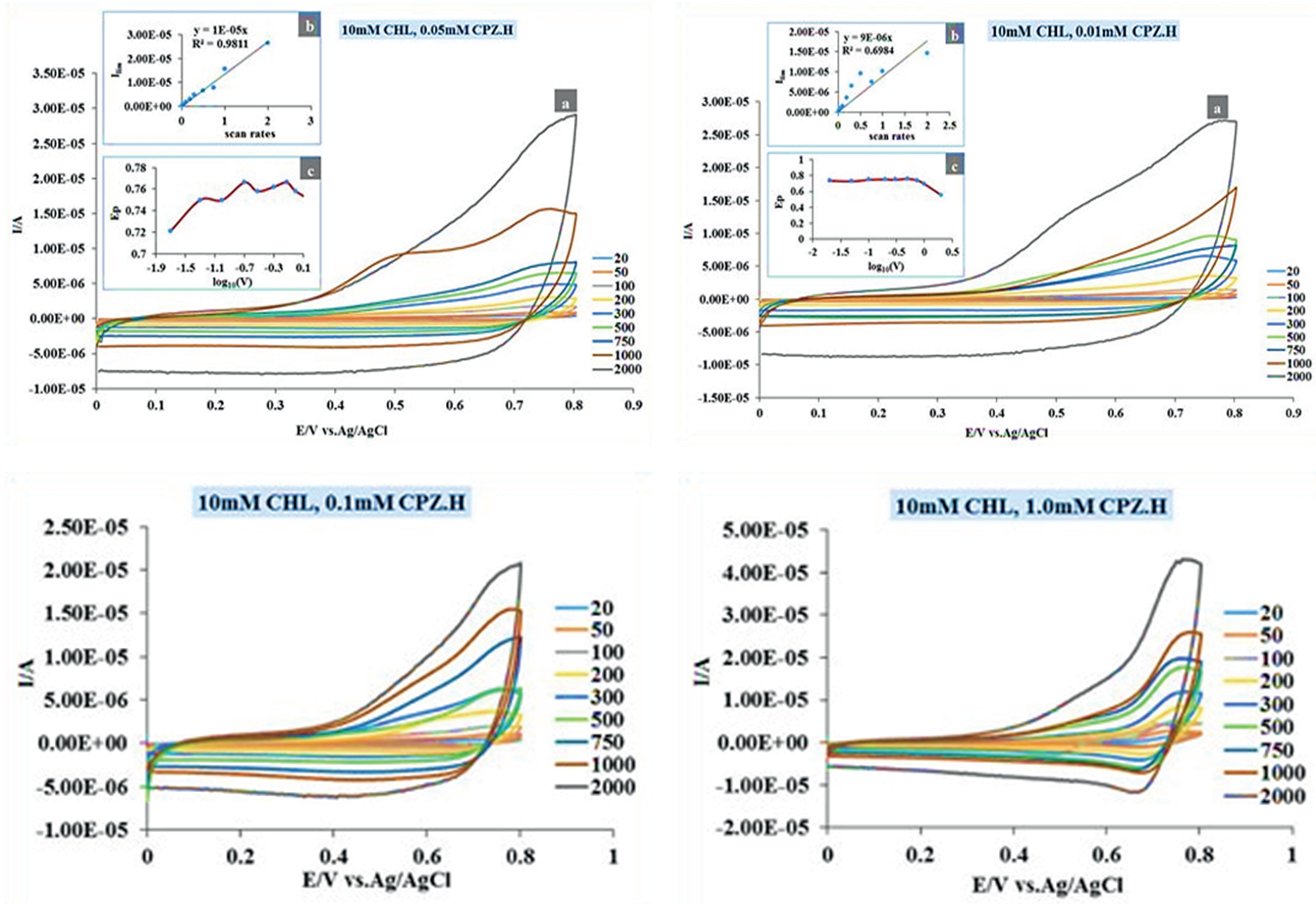

Figure 8. (a). CVs of $10 \mathrm{mM} \mathrm{CHL} \mathrm{with} \mathrm{varying} \mathrm{concentrations} \mathrm{of} \mathrm{CPZ.H} \mathrm{at} \mathrm{different} \mathrm{scan} \mathrm{rates} \mathrm{20-2000}$ $\mathrm{mV} \mathrm{s}^{-1}$, (b). The plot of peak current against scan rates and (c). The plot of peak potential against logarithms of scan rates for the oxidation process.

As a result of using different electroactive species, it is clear that the best one is KI due to the correspondence in both current and potential peaks. The reactions on the electrode surface were taking place between adsorbed CHL and active molecules. Thus, the reaction in the bulk solution will be the next study.

\section{ELECTROCHEMICAL STUDIES OF CHL IN THE BULK SOLUTION}

The above study investigated the electrochemistry of CHL on the electrode surface. In this part, we will first elucidate the electron transfer in the bulk solution between CHL and a more easily oxidised substance such as $\mathrm{KI}$ in the presence and absence of anionic surfactant such as Triton X 100. Secondly, we will extract chlorophyll pigment from fresh spinach and then study its characteristics in the presence of vitamin $\mathrm{K}_{1}$ and Triton X 100. The latter material will enhance the electrochemical reaction by reducing the surface tension at the electrode surface or the electrode/electrolyte interface, thus making molecules spread more easily.

\section{VOLTAMMETRY OF CHL WITH THE IN- TRODUCTION OF SURFACTANT}

The electron transfer between electroactive species in bulk solution was elucidated. The initial examination was the effect of Triton X 100 on the electron transfer of CHL at various concentrations $(0.05,0.1$, 0.2 , and $0.5 \mathrm{mM})$ in $0.1 \mathrm{M} \mathrm{HCl}$ by using cyclic voltammetry, see Figure 9 (A). 

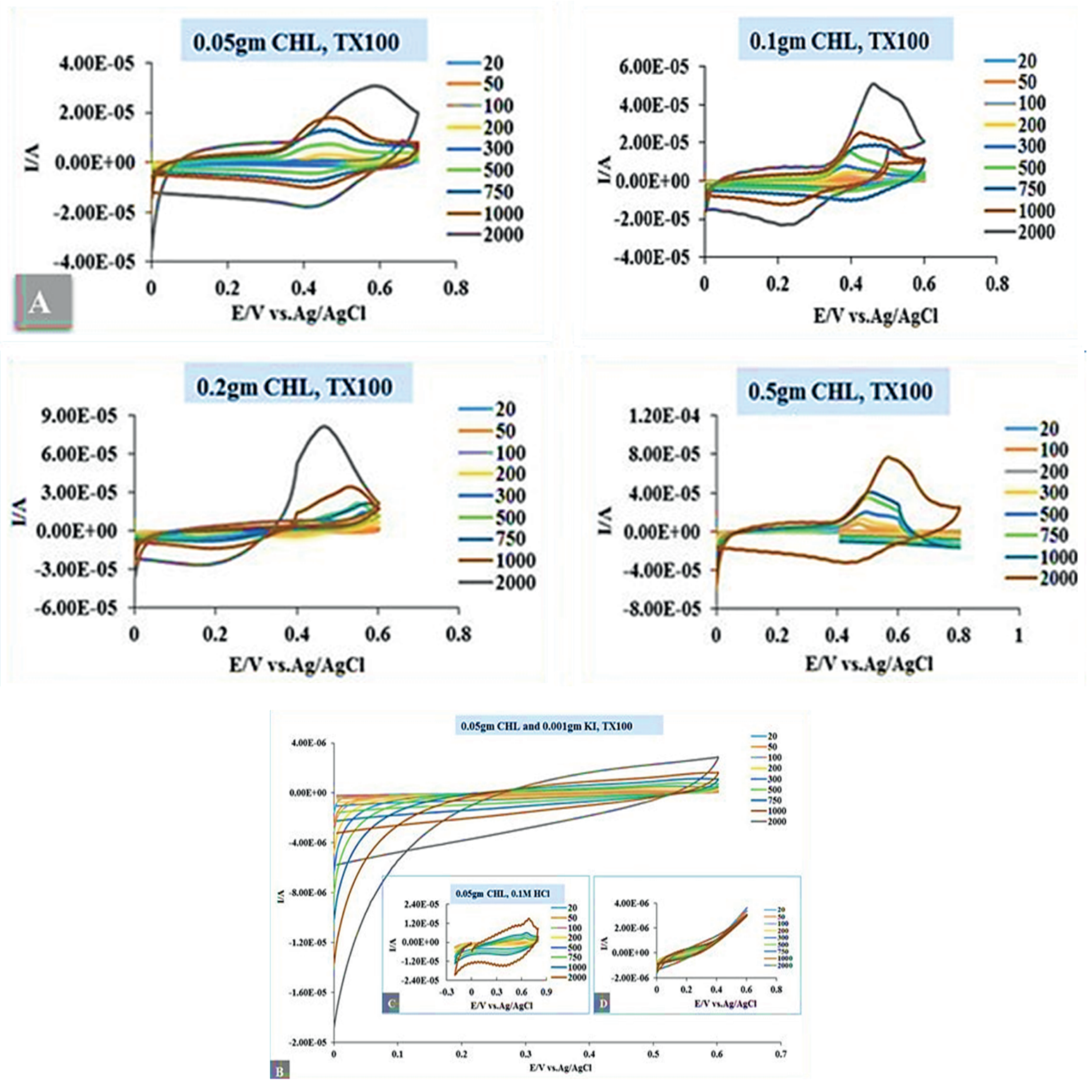

Figure 9. (A): CVs of varying concentrations of CHL in aqueous solution with $\mathrm{T} X 100$ presence at different scan rates $\left(20-2000 \mathrm{mV} \mathrm{s}^{-1}\right)$ ), (B). CVs are detailing $0.05 \mathrm{gm} \mathrm{CHL}$ in an aqueous solution containing $0.001 \mathrm{gm} \mathrm{KI}$ and 50\% T X 100. Inset, (C). CVs of 0.05gm CHL in $0.1 \mathrm{M} \mathrm{HCl}$ and (D). CVs of T X 100 in solution involving $0.05 \mathrm{gm} \mathrm{KI}$

The forward and reverse peak currents of the response of CHL were increased in the presence of $\mathrm{T}$ $\mathrm{X} 100$ in all concentrations (Fig.A). These peaks are positioned with a slight negative shift in potentials with increasing scan rate as compared with (Fig.C), suggesting that some materials were absorbed on the electrode surface. To understand the process in more detail, the scan rate dependent experiment of CHL oxidation was undertaken in the presence of TX 100 and an active species such as KI, see (Fig.B). It can be seen that the oxidative and reductive peaks current are not clear, which means that the electron transfer process in bulk solution is not readily apparent. Single-electron-oxidation between active species in the bulk solution can be assumed following this mechanism:

$$
\begin{gathered}
\mathrm{CHL}-e^{-} \leftrightharpoons \mathrm{CHL}^{+} \\
\mathrm{I}^{-}-e^{-} \leftrightharpoons \frac{1}{2} I_{2} \\
\mathrm{CHL}^{+}+\mathrm{I}^{-} \leftrightharpoons \mathrm{CHL}+\frac{1}{2} I_{2}
\end{gathered}
$$

Mechanism 3. Single-electron transferring in bulk solution 
Fig.C shows the response of CHL pigment in an aqueous solution only; there is a well-defined oxidation peak at $\quad+0.65$ due to the single oxidation on the gold electrode itself to form the stable chemical cation, shown in the below mechanism:

$6 \mathrm{Cl}^{-}+\mathrm{Au}-3 \boldsymbol{e}^{-} \leftrightharpoons \mathrm{Au}_{2} \mathrm{O}_{2}(s) \rightarrow \mathrm{Au}^{+3}(\mathrm{aq})$

Mechanism 4. One-electron oxidation on the gold electrode surface

To determine whether the same effects are observed using TX 100 to enhance the electrochemical process, the voltammetry of hydrophobic molecules

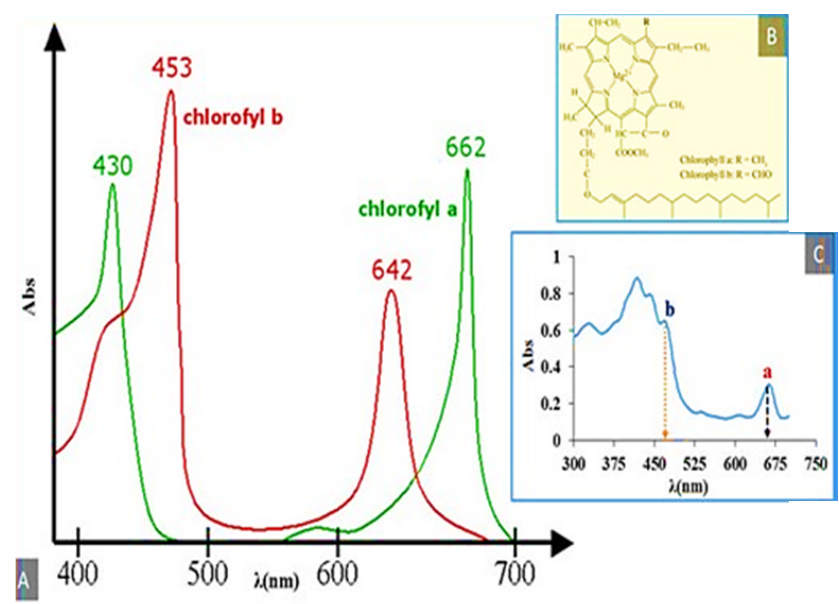

Figure 10 the left side: A. Typical wavelength of chlorophyll, B. Chlorophyll structure and C. wavelength of chlorophyll in the fresh spinach leaves. The right side: Absorption spectrum of chlorophyll derivative (chlorophyllin)

It is clear that the principal bands of chlorophyll a and $\mathrm{b}$ in the typical sample are in a similar position in the extracted pigment, while Figure 6.10 presents the shifting to low wavelength in both of these bands for chlorophyllin due to the changing in it structure.

\section{ELUCIDATION $\mathrm{CV}_{\mathrm{S}}$ IN THE SYSTEM OF (EXTRACTION PIGMENT, TX 100 AND VI- TAMIN K)}

The cyclic voltammetry of the extracted pigment (chl) in the presence of TX 100 and vitamin $\mathrm{K}_{1}$ was examined. Figure 6.11 (A) illustrates voltammo- such as chlorophyll and vitamin $\mathrm{K}_{1}$ in the acidic electrolyte will be examined next.

\section{CHLOROPHYLL: ABSORPTION SPECTRA AND ELECTROCHEMICAL REACTION}

Chlorophyll was extracted from fresh spinach leaves using the procedure described in experimental section. Figure 10 ( $\mathrm{A}$ and $\mathrm{B}$ ) the left side show the wavelengths of a standard sample of chlorophyll and its structure, while $(\mathrm{C})$ shows the recording of the absorption spectrum of chlorophyll in spinach leaves made with a UV-Visible spectrophotometer.

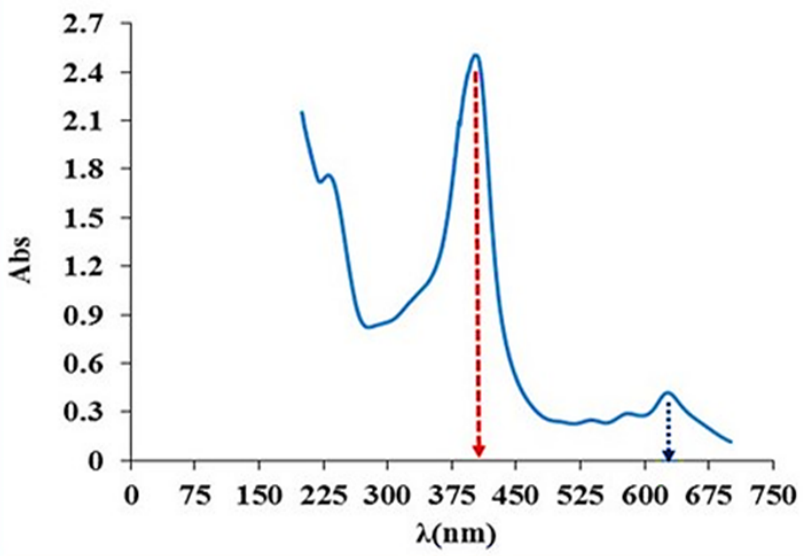

grams in varying scan rates $\left(20-1000 \mathrm{mV} \mathrm{s}^{-1}\right)$ corresponding to the redox reaction on the surface of the AuE with $50 \%$ by weight of TX 100 in $0.1 \mathrm{M} \mathrm{HCl}$. As shown in the same figure (insets B and C), both oxidative and reductive peak currents increased with the increase in scan rates. Both forward and backward peak potentials remained in the same position, indicating that the product in the surfactant phase is stable, although vitamin $\mathrm{K}_{1}$ is expected to reside within T X 100 due to its hydrophobic property. In addition, single-electron transfer between chl and vitamin $\mathrm{K}_{1}$ becomes easier. The mechanism of this reaction is shown below:

$$
\begin{gathered}
\operatorname{chl}-e^{-} \rightarrow \operatorname{chl}^{+} \\
c h l^{+}+V K_{1} \rightarrow \operatorname{chl}+V K_{1}^{+}
\end{gathered}
$$

Mechanism 5. Chlorophyll with vitamin K1 


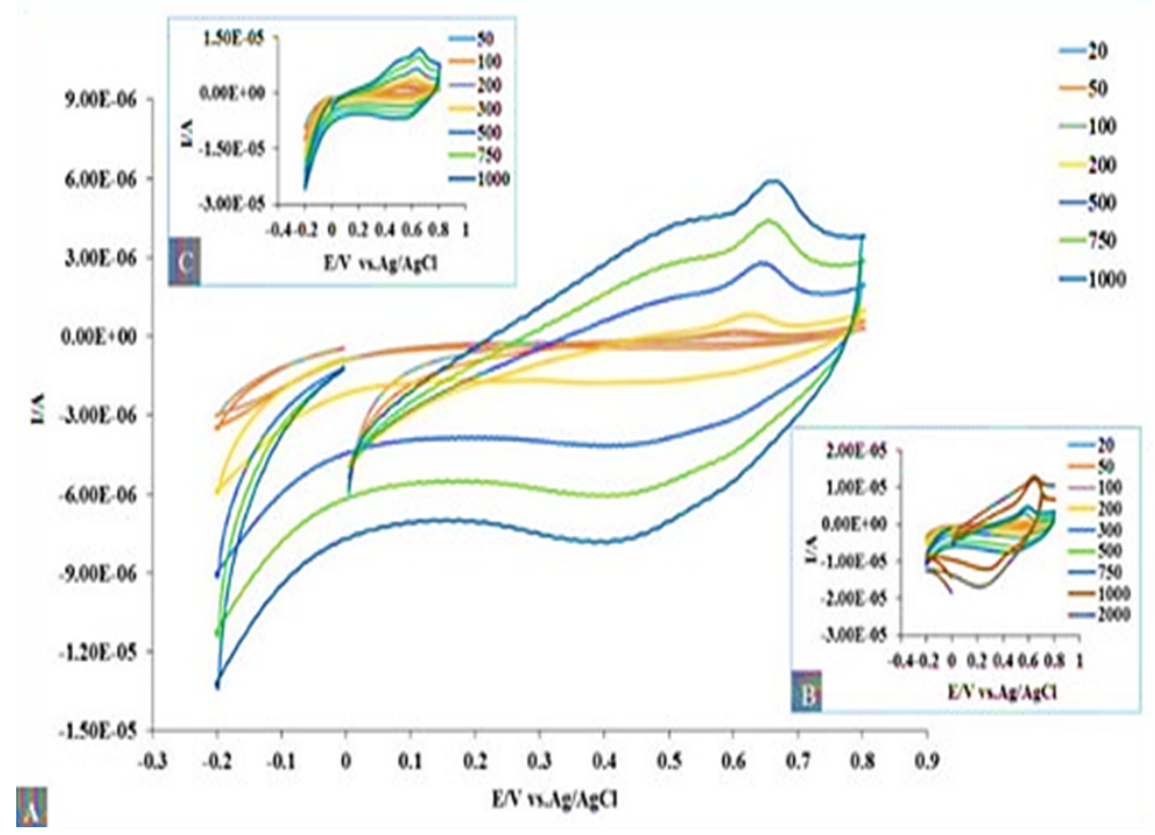

Figure 11. (A). CVs of TX100 in aqueous $0.1 \mathrm{M} \mathrm{HCl}$ at different scan rates $20-1000 \mathrm{mV} \mathrm{s}^{-1}$. Inset (B). CV s of (A) detailing of $0.0075 \mathrm{gm} c h l$ and $(C): C V s$ of $(B)$ in the presence of vitamin $K_{1}$

\section{CONCLUSION}

The electrochemical method showed that the cyclic voltammetry responses of adsorbing chlorophyllin pigment on the gold electrode occurred more easily in the aqueous solution than the organic solution, for all scan rates and adsorption times. Adsorbed chlorophyllin was able to participate in an electron transfer relay with iodide. The mechanism of the reaction was suggested to be a one-electron transfer. Overall, the first CV response of the environment of the gold electrode/ chlorophyllin dye interface was considered to be a quasi-reversible process and corresponds to the one-electron formation of radical cations in $\mathrm{HCl}$ solution.

In the second part of this study, the objective was to see if electro-induced, electron transfer process occurred between either extracted chlorophyll or chlorophyllin and some active species. It has been shown that, although the oxidation behaviour of the electroactive species potassium iodide is easy to see regarding the responses of current and potential peaks, it was electrochemically sufficient. Moreover, for the case of the redox reaction of the chlorophyll pigment in an aqueous solution of $\mathrm{HCl}$ in the presence of Triton X 100 and vitamin $K_{1}$, it was observed that both peaks current and potential increased with increase in the scan rates of potential due to the role of the surfactant in the bulk solution. The last part of this study has described the behaviour of extracted chl and CHL in KI solution with and without Triton $\mathrm{X} 100$ and vitamin $\mathrm{K}_{1}$. The results established that TritonX100 enhanced electron transfer in bulk solution due to the correspondence of the peak current and peak potential, while potassium iodide inhibits it in the previous solution. Finally, the mechanism of the reaction was suggested to be one-electron transfer; it is EC' reaction.

\section{ACKNOWLEDGMENT}

HAS would like to thank the Iraqi Ministry of Higher Education and Scientific Research (HESR), the Iraqi attaché in London and Ireland, and the University of Babylon for their financial support. NAA thanks the Royal Embassy of Saudi Arabia for financial support and the University of Jaddah. JDW would like to acknowledge the Engineering and Physical Sciences Research Council for financing this work. 


\section{REFERENCES}

1. Polo AS, Murakami Iha NY. Blue sensitizers for solar cells: Natural dyes from Calafate and Jaboticaba. Sol Energy Mater Sol Cells, . 2006;90(13):1936-44. https://doi.org/10.1016/i.solmat.2006.02.006

2. Sinha K, Saha PD, Datta S. Extraction of natural dye from petals of Flame of forest (Butea monosperma) flower: Process optimization using response surface methodology (RSM). Dyes Pigments,. 2012;94(2):212-6.

https://doi.org/10.1016/i.dyepig.2012.01.008

3. Al-Bat'hi SA, Alaei I, Sopyan I. Natural photosensitizers for dye sensitized solar cells. International Journal of Renewable Energy Research. 2013;3(1):138-43.

4. Abdel-Latif MS, El-Agez TM, Taya SA, Batniji AY, El-Ghamri HS. Plant seeds-based dye-sensitized solar cells. Mater Sci Appl, . 2013;4(09):516. https://doi.org/10.4236/msa.2013.49063

5. Grätzel M. Dye-sensitized solar cells. J Photochem Photobiol C: Photochem Rev, . 2003;4(2):145-53. https://doi.org/10.1016/S1389-5567(03)000261

6. Wongcharee K, Meeyoo V, Chavadej S. Dye-sensitized solar cell using natural dyes extracted from rosella and blue pea flowers. Sol Energy, . 2007;91(7):566-71.

https://doi.org/10.1016/j.solmat.2006.11.005

7. Hao S, Wu J, Huang Y, Lin J. Natural dyes as photosensitizers for dye-sensitized solar cell. Solar Energy. 2006;80(2):209-14. https://doi.org/10.1016/j.solener.2005.05.009

8. LuqueA,HegedusS. Handbook of photovoltaicscience and engineering: John Wiley \& Sons; 2011. https://doi.org/10.1002/9780470974704

9. Yazie N, Worku D, Reda A. Natural dye as light-harvesting pigments for quasi-solid-state dye-sensitized solar cells. Mater RenewSustain Energy,. 2016;5(3):13.

https://doi.org/10.1007/s40243-016-0077-x

10. Cherepy NJ, Smestad GP, Grätzel M, Zhang JZ. Ultrafast Electron Injection: Implications for a Photoelectrochemical Cell Utilizing an Anthocyanin Dye-Sensitized TiO 2 Nanocrystalline Electrode Nerine. J Phys Chem,. 1997;101:9342-51. https://doi.org/10.1021/jp972197w
11. Nwanya A, Ugwuoke P, Ejikeme P, Oparaku O, Ezema F. Jathropha curcas and citrus aurantium leaves dye extract for use in dye sensitized solar cell with TiO2films. Int J Electrochem Sci, . 2012;7:11219-35.

12. Li Y, Ku S-H, Chen S-M, Ali MA, AlHemaid FM. Photoelectrochemistry for red cabbage extract as natural dye to develop a dye-sensitized solar cells. Int J Electrochem Sci,. 2013;8(1):1237-45.

13. Tumolo T, Lanfer-Marquez UM. Copper chlorophyllin: A food colorant with bioactive properties? Food Res Int, . 2012;46(2):451-9. https://doi.org/10.1016/j.foodres.2011.10.031

14. Scheer H. Structure and occurence of chlorophylls. 1991.

15. Kephart JC. Chlorophyll derivatives-Their chemistry? commercial preparation and uses. Econ Bot. 1955;9(1):3-38. https://doi.org/10.1007/BF02984956

16. Robinson DS. Food-biochemistry and nutritional value: Longman Scientific \& Technical; 1987.

17. Mortensen A, Geppel A. HPLC-MS analysis of the green food colorant sodium copper chlorophyllin. Innov food sci \& emerg Technol, . 2007;8(3):419-25.

https://doi.org/10.1016/j.ifset.2007.03.018

18. Spikes JD, Bommer JC. Chlorophyll and related pigments as photosensitizers in biology and medicine. Chlorophylls. 1991:1181-204.

19. Packer M, Carver JR, Rodeheffer RJ, Ivanhoe RJ, DiBianco R, Zeldis SM, et al. Effect of oral milrinone on mortality in severe chronic heart failure. New England Journal of Medicine. 1991;325(21):1468-75.

https://doi.org/10.1056/ NEJM199111213252103

20.Pemberton R, Amine A, Hart JP. Voltammetric behavior of chlorophyll a at a screen-printed carbon electrode and its potential role as a biomarker for monitoring fecal contamination. Anal Lett, 2004;37(8):1625-43.

https://doi.org/10.1081/AL-120037592

21. Fajer J, Borg D, Forman A, Felton R, Dolphin $\mathrm{D}$, Vegh L. The cation radicals of free base and zinc bacteriochlorin, bacteriochlorophyll, and bacteriopheophytin. Proc Natl Acad Sci, . 1974;71(3):994-8.

https://doi.org/10.1073/pnas.71.3.994 
22. Kobayashi M, Ohashi S, Iwamoto K, Shiraiwa Y, Kato Y, Watanabe T. Redox potential of chlorophyll d in vitro. Biochim Biophys Acta, Bioenerg, . 2007;1767(6):596-602.

https://doi.org/10.1016/j.bbabio.2007.02.015

23. Geskes C, Meyer M, Fischer M, Scheer H, Heinze J. Electrochemical investigation of modified photosynthetic pigments. J Phys Chem,. 1995;99(50):17669-72.

https://doi.org/10.1021/j100050a001

24. Vernon LP, Seely GR. The chlorophylls: Academic press; 2014.

25.Zuber H, Cogdell RJ. Structure and organization of purple bacterial antenna complexes. Anoxygenic photosynthetic bacteria: Springer; 1995. p. 315-48.

https://doi.org/10.1007/0-306-47954-0 16

26. Parusel AB, Grimme S. A theoretical study of the excited states of chlorophyll a and pheophytin a. J Phys Chem B,. 2000;104(22):5395-8. https://doi.org/10.1021/jp000346w

27. Inanç AL. Chlorophyll: Structural Properties, Health Benefits and Its Occurrence in Virgin Olive Oils. Academic Food Journal/Akademik GIDA,. 2011.

28. Chitta R, D’Souza F. Self-assembled tetrapyrrole-fullerene and tetrapyrrole-carbon nanotube donor-acceptor hybrids for light induced electron transfer applications. J Mater Chem,. 2008;18(13):1440-71.

https://doi.org/10.1039/b717502g

29. Barazzouk S, Kamat PV, Hotchandani S. Photoinduced Electron Transfer between Chlorophyll a and Gold Nanoparticles. The Journal of Physical Chemistry B. 2005;109(2):716-23.

https://doi.org/10.1021/jp046474s

30.Wiederrecht GP, Svec WA, Niemczyk MP, Wasielewski MR. Femtosecond transient grating studies of chlorophylls and a chlorophyll-based electron donor-acceptor molecule. J Phys Chem, . 1995;99(21):8918-26.

https://doi.org/10.1021/j100021a069

31. Novak I, Komorsky-Lovrić Š. Square-Wave Voltammetry of Sodium Copper Chlorophyllin on Glassy-Carbon and Paraffin-Impregnated Graphite Electrode. Electroanalysis. 2012;24(10):195765. https://doi.org/10.1002/elan.201200315

32. Wrzosek B, Bukowska J. Molecular structure of 3-amino-5-mercapto-1, 2, 4-triazole self-assem- bled monolayers on Ag and Au surfaces. J Phys Chem C,. 2007;111(46):17397-403.

https://doi.org/10.1021/jp075442c

33.Lee S, Park J, Ragan R, Kim S, Lee Z, Lim DK, et al. Self-assembled monolayers on Pt (111): molecular packing structure and strain effects observed by scanning tunneling microscopy. J Am Chem Soc,. 2006;128(17):5745-50.

https://doi.org/10.1021/ja058037c

34.Seger B, Kamat PV. Electrocatalytically active graphene-platinum nanocomposites. Role of 2-D carbon support in PEM fuel cells. J Phys Chem C,. 2009;113(19):7990-5.

https://doi.org/10.1021/jp900360k

35. Nicol MJ. The anodic behaviour of gold. Gold Bull, . 1980;13(2):46-55.

https://doi.org/10.1007/BF03215452

36. Tremiliosi-Filho G, Dall'Antonia LH, Jerkiewicz G. Growth of surface oxides on gold electrodes under well-defined potential, time and temperature conditions. J Electroanal Chem, . 2005;578(1):1-8.

https://doi.org/10.1016/j.jelechem.2004.12.007

37. Montilla F, Morallon E, Vázquez J. Electrochemical behaviour of benzoic acid on platinum and gold electrodes. Langmuir, . 2003;19(24):10241-6. https://doi.org/10.1021/la0346705

38.Zhao G-C, Zhang L, Wei X-W, Yang Z-S. Myoglobin on multi-walled carbon nanotubes modified electrode: direct electrochemistry and electrocatalysis. Electrochem Commun. 2003;5(9):825-9. https://doi.org/10.1016/j.elecom.2003.07.006

39. Cheng G, Zhao J, Tu Y, He P, Fang Y. A sensitive DNA electrochemical biosensor based on magnetite with a glassy carbon electrode modified by muti-walled carbon nanotubes in polypyrrole. Anal Chim Acta, . 2005;533(1):11-6.

https://doi.org/10.1016/j.aca.2004.10.044

40.Goyal RN, Gupta VK, Bachheti N, Sharma RA. Electrochemical Sensor for the Determination of Dopamine in Presence of High Concentration of Ascorbic Acid Using a Fullerene-C60 Coated Gold Electrode. Electroanal, . 2008;20(7):757-64. https://doi.org/10.1002/elan.200704073

41. Bard AJ. Photoelectrochemistry and heterogeneous photo-catalysis at semiconductors. J Photochem,. 1979;10(1):59-75.

https://doi.org/10.1016/0047-2670(79)80037-4 
42. Wang J. Analytical electrochemistry: John Wiley \& Sons; 2006. https://doi.org/10.1002/0471790303

43. Guadalupe AR, Abruna HD. Electroanalysis with chemically modified electrodes. Anal Chem,. 1985;57(1):142-9. https://doi.org/10.1021/ac00279a036

44. Wring SA, Hart JP. Chemically modified, carbon-based electrodes and their application as electrochemical sensors for the analysis of biologically important compounds. A review. Analyst,. 1992;117(8):1215-29. https://doi.org/10.1039/an9921701215

45.Inoue T, Kirchhoff JR. Electrochemical Detection of Thiols with a Coenzyme Pyrroloquinoline Quinone Modified Electrode. Anal Chem, . 2000;72(23):5755-60.

https://doi.org/10.1021/ac000716c

46. Goyal RN, Gupta VK, Oyama M, Bachheti N. Differential pulse voltammetric determination of paracetamol at nanogold modified indium tin oxide electrode. Electrochem Commun, . 2005;7(8):803-7.

https://doi.org/10.1016/j.elecom.2005.05.005

47. Yang W, Justin Gooding J, Brynn Hibbert D. Characterisation of gold electrodes modified with self-assembled monolayers of 1-cysteine for the adsorptive stripping analysis of copper. J Electroanal Chem, . 2001;516(1-2):10-6.

https://doi.org/10.1016/S0022-0728(01)00649_ $\underline{0}$

48. Dickinson EJ, Limon-Petersen JG, Rees NV, Compton RG. How much supporting electrolyte is required to make a cyclic voltammetry experiment quantitatively "diffusional"? A theoretical and experimental investigation. The Journal of Physical Chemistry C. 2009;113(25):11157-71. https://doi.org/10.1021/jp901628h

49. Kalinowski M. Ion-pair effects in electrochemistry of aromatic compounds influence of supporting electrolyte cations on half-wave potentials of the ketone-ketyl radical anion systems. Chemical Physics Letters. 1970;7(1):55-6.

https://doi.org/10.1016/0009-2614(70)80247-0

50.Da Silva LM, De Faria LA, Boodts JF. Electrochemical ozone production: influence of the supporting electrolyte on kinetics and current efficiency. Electrochim Acta. 2003;48(6):699-709.
https://doi.org/10.1016/S0013-4686(02)00739$\underline{9}$

51. R. D. Sandiningtyas VS, editor. Proceedings of the Third International Conference on Mathematics and Natural Sciences; Isolation of Chlorophyll a from spinach and its modification using $\mathrm{Fe}^{2+}$ in Photostability study 2010.

52. Ciesielski PN, Faulkner CJ, Irwin MT, Gregory JM, Tolk NH, Cliffel DE, et al. Enhanced photocurrent production by photosystem I multilayer assemblies. Advanced Functional Materials. 2010;20(23):4048-54.

https://doi.org/10.1002/adfm.201001193

53. Rozkiewicz DI, Ravoo BJ, Reinhoudt DN. Reversible covalent patterning of self-assembled monolayers on gold and silicon oxide surfaces. Langmuir. 2005;21(14):6337-43.

https://doi.org/10.1021/la050438i

54. Reeves SG, Hall DO. Higher plant chloroplasts and grana: General preparative procedures (excluding high carbon dioxide fixation ability chloroplasts). Methods in Enzymology (USA). 1980. https://doi.org/10.1016/S0076-6879(80)69010I

55. Baba K, Itoh S, Hastings G, Hoshina S. Photoinhibition of photosystem I electron transfer activity in isolated photosystem I preparations with different chlorophyll contents. Photosynth Res. 1996;47(2):121-30.

https://doi.org/10.1007/BF00016175

56. Housecroft CE, Constable EC. Chemistry: An introduction to organic, inorganic and physical chemistry: Pearson education; 2010.

57.Wu Z, Li M, Mullins DR, Overbury SH. Probing the surface sites of $\mathrm{CeO} 2$ nanocrystals with well-defined surface planes via methanol adsorption and desorption. ACS Catalysis. 2012;2(11):2224-34.

https://doi.org/10.1021/cs300467p

58. Housecroft CE. Chemistry an introduction to organic, inorganic and physical chemistry. In: Constable EC, editor. 4th ed. ed. Harlow: Prentice Hall; 2010.

59.Bard AJ, Faulkner LR. Fundamentals and applications. Electrochemical Methods, 2nd ed; Wiley: New York. 2001. 